\title{
EL PUERTO DE CÁDIZ Y EL ATLÁNTICO AMERICANO EN SU TRÁFICO MARÍTIMO-MERCANTIL DESDE EL DIARIO MARÍTIMO DE LA VIGÍA (1800-1840)
}

\author{
Mario Trujillo Bolio \\ CIESAS-MÉxICo
}

\section{RESUMEN}

El Diario Marítimo de la Vigía de Cádiz resulta ser un instrumento de consulta fundamental para abordar el intercambio marítimo mercantil desarrollado entre Cádiz y las colonias hispanoamericanas. Este trabajo muestra la importancia de la riqueza documental del Diario Marítimo para aquel historiador interesado en el estudio del comercio-marítimo que cobró gran significado desde el principal puerto gaditano con el Atlántico Americano y El Caribe. cantil.

Palabras claves: Cádiz, Veracruz, La Habana, Guía de Vigía, tráfico marítimo-mer-

\section{ABSTRACT}

The Maritime dairy of the Vigia de Cadiz turns out to be a fundamental tool for consulting and approaching to the maritime mercantil interchange developed between Cadiz in the hispanoamerican colonies. This article sows the importance of the documental richness of the Maritime dairy for the particular historian interested in the survey of maritime trade, which has come out with strong significance from gaditanian (gaditano) port between the Atlantic American and the Caribean. til.

Key words: Cadiz, Veracruz, Havana, dairy of the Vigia de Cádiz/ maritime mercan-

\section{PRESENTACIÓN}

Realizar la reconstrucción del tráfico marítimo mercantil internacional de las cuatro primeras décadas del siglo XIX requiere de la consulta de variados acervos para diferenciar el actuar de los comerciantes en los distintos puertos de intercambio de toda clase de productos, manufacturas, materias primas y metales preciosos. Buena parte de los estudios 
se remiten a los datos que ofrecen los ministerios de Hacienda y, en particular, a lo que ofrecen los acervos que se concentran en los ramos de Aduanas Marítimas en donde, por lo general, se realizó un estricto inventario de los productos importados o exportados, e incluso, de variados registros del llamado comercio costanero. Algunos historiadores interesados por conocer las actividades de una casa mercantil o de los hombres de negocios que sobresalieron en la sociedad decimonónica ${ }^{1}$ recurren actualmente a la consulta de archivos notariales, o bien, a un repositorio empresarial cuando tienen la fortuna de conocerlo o cuando están a disposición en archivos públicos o privados.

Existen, al mismo tiempo, otros materiales referidos al tráfico marítimo mercantil que se encuentran en las memorias de viajeros que dieron cuenta de las actividades portuarias, ${ }^{2}$ del actuar y presencia económica de los comerciantes de fines del siglo XVIII, ${ }^{3}$ de los servicios que brindaban las compañías navieras, ${ }^{4} \mathrm{y}$ descripciones pintorescas de la vida cotidiana que se tenían en las zonas comerciales y muelles de los puertos. ${ }^{5}$ Lo mismo puede decirse de los periódicos y semanarios que durante el siglo XIX sobresalieron en los puertos y que son un medio indispensable para conocer el acontecer diario que se vivió en la plaza comercial portuaria o referentes de la llegada y salida de barcos, los pasajeros que viajaban, el tipo de mercancías o productos que entraba o se enviaba al extranjero, así como noticias concernientes a las enfermedades o epidemias que, en ocasiones, azotaban a las poblaciones portuarias. ${ }^{6}$

Buena parte de los materiales de consulta mencionados no tienen por lo general una colección completa que deseara muchas veces el historiador para analizar el tema del movimiento marítimo mercantil a partir de un periodo de larga duración con el fin de conocer la participación de los empresarios o las casas mercantiles en España y los países de América Latina. Lo mismo hay que decir para el caso específico de los periódicos, dado que es muy difícil encontrar en una hemeroteca ${ }^{7}$ o en un archivo una colección determinada que dé cuenta de lo sucedido a diario o en una semana en determinado puerto. Sin

Una obra pionera sobre el estudio de los hombres de negocios establecidos en Cádiz la podemos encontrar en el trabajo de RAMOS SANTANA, Alberto: La burguesía gaditana en la época isabelina. Cádiz, Cátedra Adolfo Castro-Fundación Municipal Cultura, 1987.

2 Interesantes relatos sobre los visitantes que vivieron el Cádiz decimonónico son analizados en los capítulos relativos a El Puerto y El Comercio en el libro de RAMOS SANTANA, Alberto: Cádiz en el siglo XIX, de ciudad soberana a capital de provincia, Madrid. Silex Ediciones, 1992.

3 Dos trabajos indispensables para comprender la participación de los comerciantes gaditanos en las últimas décadas del siglo XVIII son sin duda el reciente de BUSTOS, Manuel: Cádiz y el sistema Atlántico. La ciudad, sus comerciantes y la actividad mercantil (1650-1830), Madrid, Silex Ediciones, 2005, y también el de GARCÍA-VAQUERO GONZÁLEZ, A.: Comercio colonial y guerras revolucionarias. La decadencia económica de Cádiz a raíz de la emancipación americana. Sevilla, EEEHA, 1972.

4 TRUJILlO BOLIO, Mario: El Golfo de México en la centuria decimonónica. Entornos geográficos, formación portuaria y configuración marítima. México, CIESAS-Editorial Porrúa, 2005.

5 CLAVIJO PROVENCIO, Ramón: Viajeros apasionados: testimonios de extranjeros sobre la provincia de Cádiz 1830-1930. Jerez, Caja de San Fernado de Sevilla: Diputación, 1977.

6 Sobre los diarios y guías de viajeros podemos referirnos para el caso específico de Cádiz a: CASTRO, A.: Manual del viajero en Cádiz, 1859. El de CUEVAS, J. : Cádiz y los viajeros románticos. Cádiz, 1974. Igualmente el libro de GENER CUADRADO, E.: Diario de viaje de un comerciante gaditano (1829). Cádiz, 1976.

7 Puede conocerse el movimiento marítimo en la prensa de Cádiz tanto para fines del siglo XVIII como las primeras décadas del siglo XIX a partir de los periódicos: Diario de Cádiz año 1796, Correo de Cádiz años 1794 y 1800, y el Diario Mercantil de Cádiz 1802 y 1816. 
embargo, afortunadamente, en la Biblioteca de Temas Gaditanos "Juvencio Maeztu" 8 se cuenta con un rico acervo de lo que fue el Diario Marítimo de la Vigía de Cádiz que, para el oficio de historiar, es una fuente imprescindible precisamente por los años que existen para su consulta. En esta institución se cuenta con el Diario Marítimo de la Vigía para los años de 1789-1794. No se tienen ejemplares para los años de 1795 a 1797; sin embargo, después existe de esta misma publicación una secuencia de un periodo de 1798 a 1852. Desafortunadamente, más adelante se interrumpe la colección del Diario Marítimo de la Vigía por no contarse con los años de 1853 a 1890, empero, el resguardo en esta biblioteca de todos los números de la publicación mencionada continúa para los años de 1891 a 1936, y son de gran valor para el quehacer histórico que se ocupa de los siglos XIX y XX. La calidad y cantidad de registros que diariamente o semanalmente ofrecía el Diario Marítimo de la Vigía al lector interesado en el mundo marítimo es variado y puede utilizarse desde varias perspectivas e intereses para la investigación histórica ${ }^{9}$. En este sentido, el objetivo de este trabajo es hacer un análisis documental del Diario Marítimo de Vigía como fuente necesaria para todos aquellos interesados en el estudio histórico del acontecer portuario y el comercio marítimo que, durante la primera mitad del siglo XIX, se conoció desde la bahía de Cádiz y los puertos del Atlántico Americano.

\section{LA IMPORTANCIA DEL DIARIO MARÍTIMO DE LA VIGÍA}

El Diario Marítimo de la Vigía elaborado de manera sistemática los 365 días del año por un alto funcionario del puerto de Cádiz es posible conocerse en su versión manuscrita o través de las hojas impresas diariamente o cada semana. La información es, sin duda, abundante pues contó con varias secciones que puntualmente se nutrían con el tráfico del mundo marítimo y portuario de la bahía de Cádiz y de sus vínculos con el mundo Atlántico Americano, el Mediterráneo y el Norte de Europa. De entrada, la publicación de Diario Marítimo de la Vigía tuvo como objetivo dar cuanta a sus lectores de la climatología que se tenía en la bahía de Cádiz dando el rumbo de los vientos y las mareas en el día y la mañana. Esta información, dicho sea de paso, y por los datos que contiene la publicación, resulta ser muy valiosa para geógrafos, biólogos y físicos que, al recurrir a las series de registros ambientales del pasado, pueden prevenir desastres naturales o advertir sobre cambios climáticos.

Pero, sin duda, las secciones más imprescindibles para el quehacer historiográfico del Diario Marítimo de la Vigía son las secciones de Entrados, Salidos, Buques a la carga y Avisos pues, en ellas, podemos encontrar material suficiente para el balance histórico con

8 Quiero señalar que este trabajo no podría haberse realizado sin la amable atención prestada por Esperanza Salas Gallego, directora de la Biblioteca de Temas Gaditanos, por ello quiero agradecer el haberme mostrado, con la paciencia que le caracteriza, el Diario Marítimo de la Vigía de Cádiz: los libros referidos a los años de 1798 a 1850, e igualmente, por haberme indicado la importancia y limitaciones de esta valiosa fuente de consulta para la investigación histórica.

9 Afortunadamente María José Portela y Alberto J. Gullón escribieron un interesante balance en donde ya advertían la importancia de esta fuente para el comercio regional de Andalucía. En su estudio destacan las características del movimiento marítimo y costanero, las mercancías intercambiadas, las rutas desde Cádiz con los puertos ingleses así como algunas de las particularidades del comercio de España con América y el Caribe durante el último cuarto del siglo XIX. Al respecto véase GULLÓN, Alberto y María José PORTELA: "Los partes oficiales de Cádiz: Análisis y posibilidades de una fuente (1890) “, 1995, Baluarte, núm.1. pp. 63-78. 
temas sugerentes como: el movimiento marítimo entre Cádiz y las colonias hispanoamericanas; la situación que guardara la Corona española en sus guerras marítimas con Inglaterra y Francia; el incremento del comercio entre España y los Estados Unidos; y las modalidades que adquiere a partir de 1825 el tráfico marítimo entre Cádiz y El Caribe, los Estados Unidos y la Europa del Norte y Mediterránea.

\section{CÁDIZ PRINCIPAL CENTRO RECEPTOR Y DISTRIBUIDOR DE PRODUCTOS DE LAS COLONIAS HISPANOAMERICANAS}

Puede decirse que los años de 1792 a 1795 fueron años de bonanza económica para España como consecuencia de la promoción de las reformas borbónicas y que los conocidos almaceneros de Cádiz vinculados con los peninsulares y criollos establecidos en el puerto de Veracruz tuvieron grandes ganancias a través de la ruta trasatlántica al principal puerto novohispano como resultado del comercio libre ${ }^{10}$ En el primer cuadro que presentamos puede observarse un número significativo de embarcaciones con manufacturas y productos españoles que de Cádiz arribaron a Veracruz:

\section{BARCOS LLEGADOS A VERACRUZ PROCEDENTES DE CÁDIZ ${ }^{11}$}

$\begin{array}{lc}\text { Año } & \text { Número } \\ 1792 & 74 \\ 1793 & 56 \\ 1794 & 62 \\ 1795 & 49\end{array}$

Cabe advertir que no se cuenta con el registro de embarcaciones salidas de Cádiz a Veracruz para el año de 1796. Una de las posibles causas de la inexistencia del Diario Marítimo de la Vigía para ese año puede deberse a que el principal puerto gaditano estuvo bloqueado por las fuerzas marítimas inglesas hasta 1802, año este último en el que finalmente España e Inglaterra firmaron la paz de Aimes. ${ }^{12}$ La caída en el tráfico marítimo de Cádiz a los puertos hispanoamericanos empezó a evidenciarse ya desde 1797. Este año el Diario Marítimo de Vigía de Cádiz reporta tan sólo 4 barcos salidos del puerto gaditano a Veracruz, no obstante, Ortiz de la Tabla establece que ese mismo año al principal puerto del Golfo de México arribaron 19 barcos, muchos de los cuales contaron con la autorización de realizar el comercio de neutrales, siendo los propietarios catala-

10 Acerca de este periodo del incremento comercial véase SOUTO MANTECÓN, Matilde: Mar Abierto. La política y el comercio del consulado de Veracruz en el ocaso del sistema imperial. México, El Colegio de México-Instituto Mora, 2001, pp. 135-152.

11 La información del cuadro es obtenida de trabajos pioneros para el estudio del tráfico marítimo entre España y sus colonias hispanoamericanas, nos referimos a los estudios de SMITH, R. S. :"Shipping in the port of Veracruz, 1729-1821", en The Hispanic American Histrorical Reviw, vol, XXII, núm.1, 1943; y al libro de ORTIZ DE LA TABLA, Javier: Comercio exterior de Veracruz 1791-1792, Crisis de la dependencia. Sevilla, Escuela de Estudios Hispanoaméricnos, 1978.

12 RAMOS SANTANA, Alberto, 1987, op. cit. 
nes e ingleses. ${ }^{13}$ El Diario Marítimo de la Vigía contabilizó para el año de 1798 la salida de 38 barcos de Cádiz a Veracruz. En el año de 1799 se volvió a repetir la misma cifra de 38 embarcaciones con el similar trayecto, situación que indica una mejoría pasajera en el movimiento marítimo mercantil entre Cádiz y Veracruz.

El cuadro que a continuación presentamos es un recuento más del movimiento marítimo que hemos elaborado con base en los registros anuales que a fines o a principios de año acostumbraba publicarse en las páginas del Diario Marítimo de la Vigía y que son para los años que van de 1800 a 1808. Para completar la serie agregamos datos del periódico Correo Semanario Político y Mercantil de México -del 16 de junio al 1 de diciembre de 1809 , y de enero a diciembre de 1810-, lo cual nos permite, en lo posible, completar la primera década del siglo XIX:

BARCOS DE CÁDIZ A VERACRUZ EN LA DÉCADA DE 1800

$\begin{array}{lc}\text { Año } & \text { Número } \\ 1800 & 5 \\ 1801 & 42 \\ 1802 & 46 \\ 1803 & 43 \\ 1804 & 35 \\ 1805 & 32 \\ 1806 & 17 \\ 1807 & 32 \\ 1808 & 32 \\ 1809 & 64 \\ 1810 & 66\end{array}$

El recuento del movimiento marítimo de Cádiz con las colonias hispanoamericanas, pese a que no logró superar a los setenta y cuatro barcos que Veracruz recibió en 1792, advierte cifras significativas y ello si se tiene en cuenta lo turbulenta que fue para España la década de 1800 tanto en conflictos bélicos como en la recesión económica que obligó a la Corona española a emitir vales reales, mismos que no tardaron en devaluarse. ${ }^{14}$ Esto se puede diferenciar en el número de barcos que salieron de la Península, en las mercancías que transportaron a la principal colonia americana y por las dificultades que tuvieron los comerciantes gaditanos y casas mercantiles establecidas en Cádiz durante las guerras marítimas que España tuvo nuevamente con Inglaterra y después con Francia. ${ }^{15}$ En efecto, la caída del número de barcos que llegaron a Veracruz procedentes de Cádiz y que se observa en los años de 1804 y 1805 se hace ya patente en 1806. Lo anterior fue el resultado de

13 Este dato es posible conocerlo gracias a que se publicó en Diario Marítimo de Vigía del día 1 de enero de 1798. Se publicó un recuento de todas las embarcaciones entradas y salidas a Cádiz durante el año 1797, en donde aparece el registro para Veracruz de tan sólo 4 embarcaciones. La cifra de los 19 barcos puede verse en ORTIZ DE LA TABLA, J., 1978, op. cit.

14 HALPERIN DONGHI, Tulio: Reformas y disolución de los imperios ibéricos 1750-1850. Historia de América Latina. Barcelona, Alianza América, 1985, pp. 80-122.

15 Sobre el seguimiento de las casas mercantiles gaditanas y las dificultades que presentaron durante todo el siglo XVIII y los años de las guerras marítimas consúltese el interesante trabajo de BUSTO, Manuel, 2005, op. cit. 
la propia preparación de la guerra marítima y después las consecuencias sufridas por los aliados España y Francia ante el triunfo de Inglaterra en la batalla de Trafalgar los días 21 y 22 de octubre de $1805 .{ }^{16}$ Después del sitio de Cádiz ${ }^{17}$ por los franceses en febrero de 1806 , la salida de barcos a Veracruz fue difícil pero, pese a las diversas dificultades, los españoles desde Cádiz lograron la salida a Veracruz de 17 barcos.

Lo interesante del movimiento marítimo mercantil entre Cádiz y Veracruz es que entre los años de 1808 y 1810 éste se incrementó notablemente y benefició a comerciantes peninsulares y criollos del Consulado de Veracruz. ${ }^{18}$ Lo anterior se debió a la misma situación que creó el conflicto bélico entre España y Francia, en donde el puerto de Cádiz fue asediado en 1810 y bombardeado sistemáticamente en 1811, esto es, en el marco de lo que se conoce como la Guerra de Independencia Española contra el Imperio de Napoleón Bonaparte ${ }^{19}$, y que provocara durante y después del conflicto bélico una situación recesiva de las finanzas públicas de España. ${ }^{20}$

Hay que subrayar que durante el año de 1808 a Veracruz llegaron procedentes de Cádiz 32 barcos y, en 1809, según la fuente que nos da el periódico mexicano sumaron 64 barcos los que recibió el primer puerto. Por la información contenida en Diario Marítimo de la Vigía de Cádiz, hemos constatado que en el transcurso de la Guerra de Independencia de México, el tráfico entre Cádiz-Veracruz y Veracruz-Cádiz se mantuvo estable y con un intercambio marítimo-mercantil favorable para la Metrópoli. ${ }^{21}$ En consecuencia, tenemos que en septiembre de 1810 que inicia la insurrección armada en el Occidente de México, no fue gran obstáculo para que a Veracruz llegaran sin problemas 66 barcos españoles procedentes de Cádiz.

Aparentemente, los años de 1809 y 1810 anunciaban un nuevo auge en el movimiento marítimo entre la Metrópoli y su principal colonia. Sin embargo, y como veremos más adelante, el tráfico además de ser desigual para la Nueva España será orientado por la Corona española a obtener excedentes para sufragar los gastos de las guerras navales, ${ }^{22}$ igualmente a que comerciantes de Cádiz obtuvieran metales preciosos para realizar transacciones y vender el máximo posible de materias primas al demandante mercado europeo y así evitar las quiebras de sus casas mercantiles.

16 Véase a este respecto el artículo de BUTRÓN, Gonzalo: "La Batalla de Trafalgar y la Europa de su tiempo", en: RAMOS SANTANA, A. (editor) : En torno a Trafalgar. Cádiz, Mancomunidad de Municipios de la Comarca de La Janda, 2004, pp. 13-37.

17 Sobre la situación en que quedaron los buques de la armada española y varias embarcaciones mercantes que se utilizaron para la batalla de Trafalgar consúltese el trabajo de MÁRQUEZ CARMONA, Lourdes: "Las secuelas de la batalla", que aparece también en el libro: En torno a Trafalgar, 2004, op. cit. pp. 44-63.

18 A este respecto véase BOOKER, Jackie Robinson: Veracruz Merchants, 1770-1829: a mercantil elite in late Bourbon and early independent México. Bulder, Colorado, Westview Press (Dellplain Latin American Studies, num. 29), 1993.

19 Se puede conocer la situación de asedio y de guerra que guardaba Cádiz en los años de 1810 y 1811 en la obra de RAMOS SANTANA, Alberto, op. cit. 1992, pp. 171-176.

20 Véase al respecto FONTANA, Joseph : "La financiación de la Guerra de Independencia”. Madrid, Hacienda Pública Española, núm. 69, 1981, pp. 209-217.

21 Véase la obra de MERINO, José Patricio: Las cuentas de la Administración central española, 1750-1820, Madrid, Instituto de Estudios Fiscales, 1981.

22 Sobre las enormes transferencias de excedentes en metales preciosos y dinero amonedado durante los últimos años de las reformas borbónicas consúltese el artículo de MARICHAL, Carlos: "Beneficios y costes fiscales del colonialismo: remesas americanas a España, 1760-1814”, Revista de Historia Económica, no. 3, 1997, pp. 475505. Y también el ensayo de JIMÉNEZ CODINACH, Guadalupe: "Veracruz, almacén de plata en el Atlántico. La casa Gordon y Murphy, 1805-1824”, Historia Mexicana, núm. 2, 1988, pp. 325-353. 
El siguiente cuadro en donde se indica el movimiento marítimo de España-Veracruz y de Veracruz-Cádiz nos permite hacer las primeras observaciones sobre el tráfico de barcos en los momentos en que durara el movimiento de independencia de México, así como los momentos en donde España ya no contará con sus colonias americanas:

\begin{tabular}{lclc}
\multicolumn{2}{l}{$\begin{array}{l}\text { Embarcaciones procedentes de } \\
\text { España a Veracruz }\end{array}$} & \multicolumn{2}{l}{$\begin{array}{l}\text { Embarcaciones salidas de Veracruz } \\
\text { a Cádiz }\end{array}$} \\
Año & Número & Año & Número \\
1812 & 41 & 1812 & 8 \\
1813 & 31 & 1813 & 1 \\
1814 & 20 & 1814 & 25 \\
1815 & 59 & 1815 & 22 \\
1816 & 34 & 1816 & 26 \\
1817 & 48 & 1817 & 16 \\
1818 & 46 & 1818 & 11 \\
1819 & 37 & 1819 & 23 \\
1820 & 51 & 1820 & 19 \\
1821 & 34 & 1821 & 24 \\
1822 & 34 & 1822 & 19 \\
1823 & 5 & 1823 & 8
\end{tabular}

Si miramos con detenimiento las cifras del cuadro, encontramos que durante el transcurso de los años 1811 a 1822, en que cobra presencia el movimiento de independencia de México, es notable el número de barcos llegados de la Península -cabe decir que de Cádiz fueron el mayor número, pero también hay que tomar en cuenta que otros realizaron una escala en Cádiz después de haber salido de otros puertos españoles como Málaga, Tarragona, Santander, Vigo y la Gran Canaria- para dirigirse al entonces llamado Seno Mexicano y, concretamente, a los puertos de Veracruz y Campeche. Lo anterior indica que tanto a la Corona española como a los dueños de barcos particulares les convino tener durante dicho trayecto de tiempo las escuadras de los barcos de guerra, y sobre todo las embarcaciones mercantes españolas para que no dejaran de participar en la transportación de mercancías y productos entre las mismas colonias hispanoamericanas, fuese ello en la región del Caribe o a todo lo largo de la costa del litoral del Atlántico americano. En consecuencia, la estrategia española se centró en dos objetivos: el primero, fue defender el convoy de barcos mercantes contra los barcos ingleses; y segundo, crear las condiciones necesarias para que fueran rentables las expediciones para que fragatas y veleros, ya estando en el Atlántico Americano, pudiesen participar en el movimiento marítimo mercantil intercolonial que cobró fuerza entre Veracruz, Guayaquil, La Habana, Montevideo y, en menor medida, con el Callao. Así, tenemos que las cifras de los barcos que llegaron a Veracruz en el periodo señalado son claramente superiores a los barcos, que, procedentes de Veracruz, tuvieron como destino al puerto de Cádiz.

Lo mismo puede decirse de las embarcaciones salidas de Veracruz para dejar cargamentos en Cádiz y continuar sus travesías con tintes, plata y otros productos requeridos en los puertos de Málaga, Tarragona, Barcelona o Santander. Este mismo proceso que puede verificarse a través del Diario Marítimo de la Vigía de Cádiz y que tuvo la Península con 
otros de sus puertos no menos importantes como La Habana, Puerto Rico, Callao de Lima, Cartagena de Indias, Montevideo y Honduras, se le puede dar seguimiento a través de las distintas secciones que comentábamos anteriormente. Sea ello en la sección de Entrados después de las travesías transatlánticas desde las colonias hispanoamericanas; en la sección de Anuncios para que los cargadores preparen fletes de las mercancías y productos para El Caribe y el Golfo de México; o en los reportes de los barcos Salidos en los que se especificaba a qué puerto del Atlántico Americano irían y el consignatario a quien se le aseguraba el cargamento. ${ }^{23}$

\section{CÁDIZ, RECEPTOR DE METALES PRECIOSOS AMERICANOS PARA EL PAGO DE LAS GUERRAS MARÍTIMAS}

Son varios los ejemplos que se pueden presentar de los barcos, corbetas y fragatas de guerra que de Veracruz, Callao y en menor medida de La Habana, Cartagena de Indias y Honduras salieron en derechura para Cádiz con grandes cargamentos de oro, plata y pesos fuertes. La rica información del Diario Marítimo de la Vigía nos indica que fueron no tan sólo para la Corona, sino una parte considerable de los cargamentos fue para consignatarios o dueños de compañías-mercantiles del Consulado de Cádiz. ${ }^{24} \mathrm{Si}$ bien la llegada de remesas de metales preciosos a Cádiz fue presentada en un principio por José Canga Argüelles en los datos que aparecen en su obra: Diccionario de hacienda para el uso de los encargados de la suprema dirección de ella ${ }^{25}$ particularmente para los años de las guerras navales de España; y después Guadalupe Jiménez aportara más información, concretamente de la transportación de plata mexicana por barcos ingleses; y también fuera verificado y analizado el excedente monetario salido de Veracruz por Carlos Marichal, hay que advertir que la información de algunos años de 1798 a 1823 que contiene el Diario Marítimo de la Vigía de Cádiz es todavía más precisa, particularmente la que se desprenden de los sobordos de las embarcaciones españolas y, ocasionalmente, de la información que reportaban los barcos ingleses. Inclusive, se puede adelantar que en algunos años es más detallada esta fuente de lo que Canga Argüelles advirtiera en su Diccionario.

Otro aspecto importante que puede conocerse de la consulta del Diario Marítimo de la Vigía es cómo el comercio de tintes -grana, granilla en polvo, añil, palo de tinte de Campeche y palo del moral-que se realizaba desde Veracruz, Campeche, Honduras y Guayaquil para su envío a Cádiz resultó ser un negocio muy benéfico para los comerciantes gaditanos, particularmente en los tiempos de las guerras marítimas de España y durante los años que duraron los movimientos emancipadores de las colonias españolas americanas. Para ejemplificar todo lo anterior ofrecemos en esta ocasión algunas muestras, a ma-

23. En el Diario Marítimo de la Vigía de los años que van de 1800 a 1820, en la sección denominada Buques que están a la carga, hay un apartado específico de los barcos señalándose a qué puertos coloniales hispanoamericanos navegarían. Lo mismo puede diferenciarse en el recuento anual de entrada y salida de barcos a la bahía de Cádiz, que, como hemos mencionado, aparecía el primer día del año especificando también los de Veracruz, Campeche, el Alto Caribe, Perú y Sudamérica.

24 Un primer estudio sobre el recuento de las casas mercantiles puede conocerse en el trabajo de RUIZ RIVERA, Julian B.: El consulado de Cádiz: Matrícula de comerciantes, 1730-1823. Cádiz, Diputación Provincial, 1988.

25 CANGA ARGÜELLES, José: Diccionario de hacienda para usos de los encargados de la suprema dirección de ella. Londres, 1822. 
nera de catas, de algunos de los sobordos de los barcos que aparecen en el Diario Marítimo de Vigía de 1808 a 1824, al ilustrar muy bien las características de intercambio mercantil de Cádiz con el Atlántico Americano. La información del Diario Marítimo de la Vigía nos da el nombre de los navíos o fragatas y su nacionalidad; si las mismas eran del Reino español o de particulares españoles; o si la Corona española había contratado una embarcación inglesa para transportar caudales. Asimismo, la fuente ofrece la indicación del puerto de donde provenían; en algunos de los casos los días que se habían cumplido en la ruta trasatlántica; la fecha de llegada a Cádiz; si tuvo percances en el mar; los productos, metales preciosos y monedas, como dar la conversión de pesos fuertes en su equivalente a reales de vellón ${ }^{26}$ :

- Fragata de guerra española Malpoméne de Veracruz con 36 días, llegada a Cádiz el 24 de diciembre de 1808. Total de caudales en pesos fuertes: 1. 605,446 $6 \mathrm{Su}$ equivalente en reales vellón: 32, 108, 9218.

- Navío de S. M. San Justo de Veracruz y La Habana, llegó a Cádiz el 1 de febrero de 1809. Total de caudales en pesos fuertes: $6.753,133$ 7. Su equivalente en reales vellón: 135. 062, 67717.

- Fragata de S. M. Prueba de Montevideo, llegó a Cádiz el 1 de diciembre de 1809. Total de caudales en pesos fuertes: 152.95963 . Su equivalente en reales de vellón: 3.059, 19521.

- Navíos de S. M. Asia y Algeciras de Veracruz y La Habana, llegaron a Cádiz el 2 de mayo de 1810. Total de caudales en pesos fuertes: 4.146, 18934 . Su equivalente en reales de vellón: 82, 927, 78817.

- Navío de S. M. B. Pedro Alcántara de Callao de Lima, llegó a Cádiz el 24 de septiembre de 1810. Total de caudales: 1.726.016 5 3. Su equivalente en reales vellón: 34.520.333.

- Navío de S. M. bergantín El Impecable de Veracruz, llegó a Cádiz el 18 de febrero de 1811. Total de caudales en pesos fuertes: $1.530,000$. Su equivalente en reales de vellón: 30. 600, 000 .

- Navío de guerra español de 54 cañones Miño, de Veracruz y La Habana; salió el 16 de mayo del primer puerto y llegó al último el 6 de junio, de donde volvió a dar la vela el 10 del mismo y conduce lo siguiente:

De Veracruz pesos fuertes para el Rey.................. 1.516.280

De La Habana pesos fuertes para el Rey... 149.544

1.665 .824

De Veracruz pesos fuertes para particulares... $1.922 .98851 \frac{1}{2}$

De La Habana pesos fuertes para particulares 114.382

Suma total $3.703 .19451 \frac{1}{2}$

Los siete primeros ejemplos advierten claramente de la imperiosa necesidad del Rey por obtener considerables caudales en navíos para solventar los costes de las guerras na-

26 El seguimiento se puede realizar consultándose el Diario Marítimo de la Vigía de Cádiz durante los meses y años siguientes: diciembre de 1808 , febrero y diciembre de 1809 , mayo y septiembre de 1810 , febrero y julio de 1811. 
vales de España así como cumplir con la deuda que esta nación había establecido con Francia. Los principales abastecedores, como sucediera en los siglos XVI, XVII y XVIII, fueron los virreinatos de Nueva España y Perú, y según lo confirma la información del Diario Marítimo de Vigía en las décadas de 1810 y 1820 tampoco dejaron de serlo, dado que al término de la vida colonial la mayor parte de los metales preciosos continuó saliendo de Callao y Veracruz.

\section{EL COMERCIO DE LOS METALES Y LOS TINTES}

Los cargamentos de los barcos salidos de Veracruz y Callao a la Península a partir de 1812 no tan sólo serán para el Rey de España, sino también para consignatarios y/o dueños de casas mercantiles establecidos en Cádiz. Se advierte también un tráfico marítimo de tintes demandado por los fabricantes catalanes y navarros de textiles, y por los manufactureros holandeses, franceses y genoveses para el teñido de lanas, sedas y toda clase de hilados y tejidos de algodón y lino. Con todo, los siguientes ejemplos que mostramos a continuación y que recorren el transcurso de la década de 1810 la ruta marítima entre Cádiz y el Atlántico Americano indican no solamente que el comercio colonial se había especializado con metales preciosos y productos que en cierta forma podían solventar los problemas de la Corona española y las quiebras de las casas mercantiles establecidas en Cádiz. A este respecto recogemos una segunda cata para mostrar la información del Diario Marítimo de la Vigía ${ }^{27}$ :

- Fragata de guerra española la Venganza, de Veracruz y La Habana, llegó a Cádiz el 12 de febrero de 1813 en 52 días de navegación, con 715.181 pesos en oro y plata, 139.172 pesos en oro y plata en moneda provincial, 184.948 en oro y plata en barras y oro, 800 quintales de cobre, grana, añil, granilla, y otros efectos.

- Fragata de guerra española la Esmeralda, de Veracruz y La Habana en 57 días de navegación, entró a Cádiz el 10 de diciembre de 1814 con 1.611 .239 pesos fran$\cos 6 \frac{1}{2}$ reales en plata mexicana, 806.617 pesos y 1 real en barras quintadas en plata con 100.827 marcos, $50.2961 / 2$ pesos francos en moneda provincial y 924 moneda oro, sumado todo 2.469.077 pesos francos $31 \frac{1}{2}$ reales de plata de Veracruz.

- Fragata de guerra española Sabina de Veracruz en 63 días de navegación, entró a Cádiz el 28 de enero de 1820, con 460 sobornales de grana, 6 cajones de vainillas, 8 cajones de plata labrada, 6 barras de plata y 1.540, 282 pesos francos.

- Entró al puerto de Cádiz el 14 de febrero de 1823 la fragata española nuestra señora del las Nieves, alias la Fama de Cádiz, maestre José María de Águeda de Veracruz y La Habana en 28 días con grana, azúcar, carey, añil, polvo (tabaco), cacao, palo (de tinte), 534966 7/8 pesos fuertes en oro y plata, 276 marcos de plata labrada, 14 tejos de oro y 1 cajón de plata labrada a los señores Puente Hermano y Cía.

- Entró a Cádiz el 28 de febrero de 1824 fragata española nuestra señora de Nieves, alias la Fama de Cádiz (es la misma embarcación que aparece arriba pero un año después) de Veracruz y La Habana en 36 días con azúcar, café, gran, añil, otros

27 Diario Marítimo de la Vigía de Cádiz: febrero de 1813, diciembre de 1814, enero de 1820, febrero de 1823, y febrero de 1824. 
efectos, 2067 pesos fuertes 4 1⁄2 reales de plata, 36 onzas de oro y correspondencia para los señores Puente Hermanos. Conduce el Marqués de Cárdenas y 2 esclavos, 14 oficiales, 2 cadetes, 47 soldados y sargentos, y 30 pasajeros. Dice su capitán que a su salida de La Habana no había novedad y que se mantenían hostilidades entre el castillo de San Juan de Ulúa y Veracruz.

En los tres últimos cargamentos arriba seleccionados es evidente lo que fue la caída de las transferencias en metálico desde Veracruz y La Habana, el interés de comerciantes y consignatarios por cargar al máximo los barcos con materias primas que tenían un precio significativo en las plazas comerciales de Cádiz y Barcelona. Podemos decir también que el último manifiesto, el de la fragata de la Señora de las Nieves, es muy singular pues anuncia la pérdida de la Nueva España con lo que fue la última acción de la armada española que desde el castillo de San Juan de Ulúa bombardeó a Veracruz hasta el año de $1825 .^{28}$

\section{CÁDIZ Y LA FORMACIÓN DE LAS RUTAS MERCANTILES CON EL CARIBE Y AMÉRICA LATINA}

A partir de la segunda mitad de la década de 1820 el Diario Marítimo de la Vigía de Cádiz empieza a modificarse en su formato y en la información que ofrece. Si bien este periódico para estos años está ausente de los vínculos con los países de lo que se conocerá como América Latina, el historiador que se centre en el estudio de las relaciones comerciales de Cádiz y las colonias españolas de Puerto Rico y Cuba encontrará durante toda la primera mitad del siglo XIX un arsenal de datos relativos a la reorganización de las rutas comerciales, como la que se constituyó desde Cádiz, Gran Canaria, Puerto Rico, La Habana y Santiago de Cuba. Igualmente, referencias de los viajes directos de ida y vuelta entre Cádiz y La Habana. Lo mismo puede decirse de las peculiaridades del comercio peninsular y caribeño. Para ello damos dos manifiestos que muy bien ilustran lo que entraba a Cádiz procedente de Santiago de Cuba, publicado el 14 de enero de 1839 y del que se informaba el 15 de abril del mismo año que se enviaba desde Cádiz para La Habana:

- Sobordo del bergantín español Anita su capitán y maestre D. Manuel Sánchez que entró de Santiago de Cuba y Algeciras la noche del pasado mes (diciembre de 1838) consignado a Francisco López Domínguez: 100 cajas de azúcar, 77 pacas de algodón, 70 palos de caoba y 40 quintales de granadillo, al consignatario 4000 cigarros, a don Pedro Felipe del Campo 100 tercios de tabaco, a D. Juan Pérez 42 dichos idem, a D. Juan Rafael Doran 35 cajas de azúcar, a Martínez Pinillo Hermanos 50 dichas de idem. y un cajón con uñas de carey, a la viuda de Ravelo, 47 pacas de algodón a D. Felix García, 7 cajas de azúcar a D. Mauricio Sevil, un cajón de dulce, a don Pedro Pasquel Vela, 1000 cigarros y 2 onzas de dulce a D. Santiago Ferry.

- Cargamento que conduce para La Habana el bergantín español de 189 toneladas nuestra señora de Guadalupe su capitán y maestre don Francisco García Chicano

Sobre la presencia de la armada española en San Juan de Ulúa para sitiar a Veracruz véase: TRUJILLO BOLIO, Mario, 2005, op. cit. pp. 55-71. 
y consignatario don Juan Bautista Corveto cuyo buque salió el día 27 de marzo. 5870 botijas de aceite, 1250 cajas de fideos, 250 cuñetes de aceitunas, 100 estuches de loza vasta, 90 barriles de chorizos, 52 pipas y 3 dichas de vino tinto, 20 botas de vino tinto, 20 botas de vino blanco, 40 cajoncitos de jabón, 32 sacos de garbanzo, 3 sacos de orégano, 16 cajas con velas de sebo, 10 cajas de sanguijuelas, 6 cajas de dulce, 5 con zapatos, 3 cajas con morcilla y chorizos, 9 barrilitos de aceitunas, 9 cajones de varios efectos, uno con almendras, 3 tercios de nueces, y 3 sacos de pimienta.

El restablecimiento de las relaciones diplomáticas y comerciales entre México y España a partir del año de 1835 no se evidenció de manera inmediata en los registros del Diario Marítimo de la Vigía de Cádiz. Sin embargo, sí se observa una ruta de los barcos ingleses, norteamericanos, italianos y alemanes que cargaban mercancías y productos españoles en Cádiz y después continuaban sus travesías para dirigirse a La Habana, Veracruz y Tampico. Sin embargo, ya para el año de 1839 aparecen barcos de bandera española enviando cargamentos para La Habana y Veracruz, o directamente a este último y también al puerto de Tampico en el Golfo de México:

Cargamento que conduce para La Habana y Veracruz la fragata española Marinera su capitán y maestre don Santiago Patrón y consignatario don Miguel A. García cuyo buque salió el 18 pasado (junio de 1839):

20000 cebollas, 4057 ristras de ajos, 20016 botijas de aceite, 1300 cajas de fideos, 68 porrones con alcanciles en aceite, 77 barriles de harina, 49 barriles de vino, 50 barriles de aceitunas, 23 balones de papel blanco, 107 sacos de garbanzos, 41 sacos de arroz, 40 sacos de habas, 6 sacos de pimiento molido, 20 barriles y 2 botas de vinagre, 69 cajas de dátiles, 10 tercios de papel blanco, 7 tercios de canela, 23 fardos de cotonía para velas, 12 cajones de dulce, 11 cajones con muebles de caoba, 9 cajones de libros, 5 cajones de barajas, 4 cajones con muebles, 2 cajones con sedería y cintas, 24 cajas de sanguijuelas, 2 cajas de atún, 6 serones de nueces, 2 cajas de sedería, un cajoncito de listonería, 2 cajas de sebo, una caja con zapatos y babuchas, 2 cajones de calzado, 2 cajas de azafrán, 2 cajas de mapas, 5 pipas de aceite, un cajoncito de gasa, un baúl, un cajón y una espuerta de equipajes y herramientas de carpintería. ${ }^{29}$

Si bien es cierto que por el año de 1818 los cargamentos de los barcos españoles a la Nueva España podían contar con un tercio de textiles británicos o franceses como ruanes, bramantes, irlandesas de hilo, pañuelos de algodón, bayetas de 100 hilos y bretañas, ${ }^{30}$ hay que decir que las embarcaciones que empiezan a llegar a Veracruz a mediados de la década de 1830 ya contarán con manufacturas textiles españolas como hilo carreto, telas y prendas de vestir de la industria textil castellana y catalana, calcetas, listón, sombreros, sarguilla de seda y capicholas de Sevilla, cintería e hilos de Córdoba y León y paños de Segovia.

No obstante, en la década de 1820 se mantiene la exportación española a México de vinos y aceite de oliva del Marco de Jerez, de aguardiente catalán, pero se incorporan otros comestibles como chorizos, carne salada, salmón, arenques y cada vez más numero de con-

29 Diario Marítimo de Vigía, junio de 1839.

30 Véase al respecto Archivo General de Indias, Indiferente General, Licencias para embarques y sobrecargos números 2143 y 2144, años 1818-1819. 
servas. ${ }^{31}$ Son notables a su vez, otros productos como zapatos, pares de botas y loza. En cambio, ya es notable la exportación española a Veracruz de acero, fierro (hierro), clavos, barras de plancha de Vizcaya, clavasón de fierro (hierro). ${ }^{32}$

En contraparte, sale a fines de la década de 1830 de los puertos de Veracruz y Tampico a Cádiz la tradicional exportación mexicana como plata, plata en pasta, monedas en pesos fuertes, materias tintóreas, y cacao de Tabasco. ${ }^{33}$ En contraparte, se vana incorporar otros tantos productos más como zarzaparrilla, purga de Jalapa, juguetes de barro, anís, vainilla, cajones de droga y medicinas ${ }^{34}$.

\section{FUENTES CONSULTADAS}

Archivo General de Indias, Indiferente General: expedientes Licencias para embarques y sobrecargas, números 2143 y 2144, años 1818-1819.

\section{Periódicos}

Correo Seminario Político y Mercantil de México. Años 1809 y 1810.

Diario Marítimo de Vigía, Cádiz. Años 1797 a 1840

\section{Bibliografía}

BOOKER, Jackie Robinson: Veracruz Merchants, 1770-1829: a mercantil elite in late Bourbon and early Independent Mexico, Bulder-Colorado, Westview Press (Dellplain Latin American Studies, núm. 29), 1993.

BUTRÓN, Gonzalo: "La batalla de Trafalgar y la Europa de su tiempo" en: Alberto RAMOS (editor), En Torno a Trafalgar, Cádiz, Mancomunidad de Municipios de la Comarca de Janda, 2004.

BUSTOS, Manuel, Cádiz y el sistema Atlántico. La ciudad, sus comerciantes y la actividad mercantil (1650-1830), Madrid, Silex Ediciones, 2005.

CANGA ARGÜELLES, José, Diccionario de Hacienda para los usos de los encargados de la suprema dirección de ella, Londres, 1822.

CLAVIJO, Provencio R., Viajeros apasionados. Testimonios de extranjeros sobre la provincia de Cádiz 1830-1930, Cádiz, Diputación Provincial, 1977.

FONTANA, Joseph: "La financiación de la Guerra de Independencia", Madrid, $\mathrm{Ha}$ cienda Pública Española, 1981, no. 69, pp. 209-217.

GARCÏA-VAQUERO GONZÄLEZ, A.: Comercio colonial y guerras revolucionarias. La decadencia económica de Cádiz a raíz de la emancipación americana, Sevilla, EEEHA, 1972.

\footnotetext{
Véase Diario Marítimo de Vigía año 1836.

Diario Marítimo de Vigía año 1837.

Diario Marítimo de Vigía año 1838.

Diario Marítimo de Vigía año 1840.
} 
GULLÓN, Alberto y María José PORTELA: “Los partes oficiales de Cádiz: Análisis y posibilidades de una fuente (1890)", Cádiz, Baluarte, no.1, 1995, pp. 63-78.

HALPERIN DONGUI, Tulio: Reformas y disolución de los imperios ibéricos. Historia de América Latina, Barcelona, Alianza América, 1985.

JIMÉNEZ CODINACH, Guadalupe: "Veracruz, almacén de plata en el Atlántico. La Casa Gordon y Murphy, 1805-1824”, México, Historia Mexicana, 1988, núm.2, pp. 325-353.

MARICHAL, Carlos: "Beneficios y costes fiscales del colonialismo: las remesas americanas a España, 1760-1814", Madrid, Revista de Historia Económica, no. 3 , 1997, pp. 475-505.

MÁRQUEZ CARMONA, Lourdes: "Las secuelas de la batalla", en: Alberto RAMOS SANTANA (editor): En torno a Trafalgar, Cádiz, Mancomunidad de Municipios de la Comarca de la Janda, 2004.

MERINO, José Patricio: Las cuentas de la Administración Central Española, 1750 1820, Madrid, Instituto de Estudios Fiscales, 1981.

ORTIZ DE LA TABLA, Javier: Comercio exterior de Veracruz, 1791-1792. Crisis de independencia, Sevilla, Escuela de Estudios Hispanoamericanos, 1978,

RAMOS SANTANA, Alberto: La burguesía gaditana en la época isabelina. Cádiz, Cátedra Adolfo Castro, Fundación Municipal de Cultura, 1987.

-Cádiz en el siglo XIX, de ciudad soberana a capital de provincia, Madrid, Silex, Ediciones, 1992.

RAMOS SANTANA, Alberto (editor): En torno a Trafalgar. Cádiz, Mancomunidad de Municipios de la Comarca de la Janda, Cádiz, 2004.

SMITH, Robert S: "Shipping in the port of Veracruz, 1720-1821", en: The Hispanic American Historical Review, 1943, vol, XXII, Núm. 1.

RUIZ RIVERA, Julián B. : El consulado de Cádiz: matrícula de comerciantes, 1730 1823. Cádiz, Diputación Provincial, 1988.

SOUTO MANTECÓN, Matilde: Mar Abierto. La política y el comercio del consulado de Veracruz en el ocaso del sistema imperial. México, El Colegio de MéxicoInstituto Mora, 2001.

TRUJILLO BOLIO, Mario: El Golfo de México en la centuria decimonónica. Entornos geográficos, formación portuaria y configuración marítima. México, CIESASEditorial Porrúa, 2005. 